\title{
Mastopexy - How to Reach Consistent Results - New Methods
}

\author{
M. Sulamanidze, G. Sulamanidze and K. Sulamanidze \\ Additional information is available at the end of the chapter
}

http://dx.doi.org/10.5772/56317

\section{Introduction}

Ptosis of glandula mammaria is a well-known aesthetic deflection, which gives a woman unpleasant sensations, causing the need for cosmetic surgery in this field to consistently increase over the last several years. The central problem raised by surgeons is the achievement of a longstanding strength of form and a high glandula mammaria position after performing the operation.

There are hundreds of different surgical methods and devices for handling this problem, which are based on more or less significant solution of skin continuity, surgical release of glandula mammaria, cutting out of its parenchymatous tissue in the form of grafts, underrunning for the purposes of getting flexible stroma, cephalic redistribution of glandular tissue and anchoring to structures, such as banding of glandula mammaria musculus or periosteal coverage of feathers. In addition, it is necessary to tolerate the nipple-areola complex to a new higher location, as well as cutting out of glandula mammaria implant proportional to the modified "excipient" for getting stable dermic uplift.

Unfortunately, these approaches are quite often found to be unsuitable and do not clear away the problem of gravity post-operation ptosis over a long-term period. Suspensory skin sags, overcast seams decrease and on the back of the remained nipple-areola complex in the high position, the whole stroma of the glandula mammaria sinks down gradually, making the previously achieved rather good results ineffective (figure 1a, b, c) $[1,2,3,4,5,6]$.

In this case there occurs a relative desolation of the glandula mammaria top hemisphere, an overflow of the lower hemisphere, a flattering of glandula mammarias and its spreading on the chest wall. Visible seams aggravate the aesthetic failure of the performed operation. 


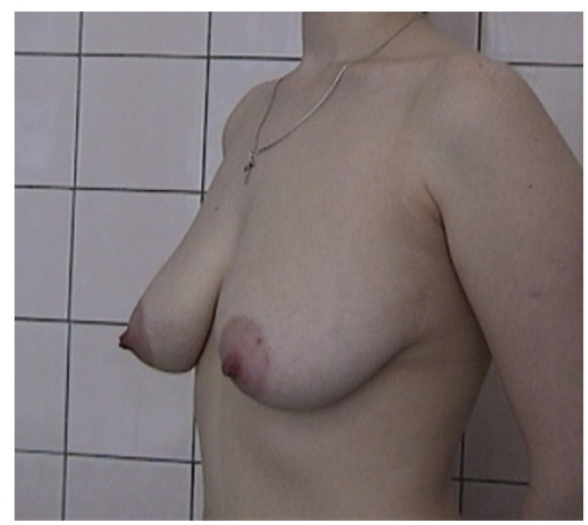

a

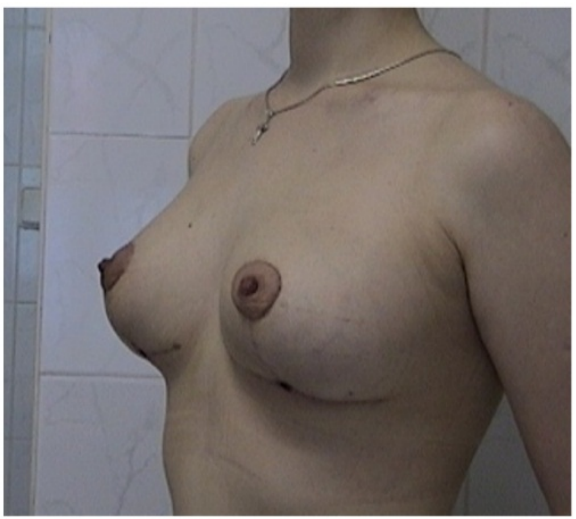

b

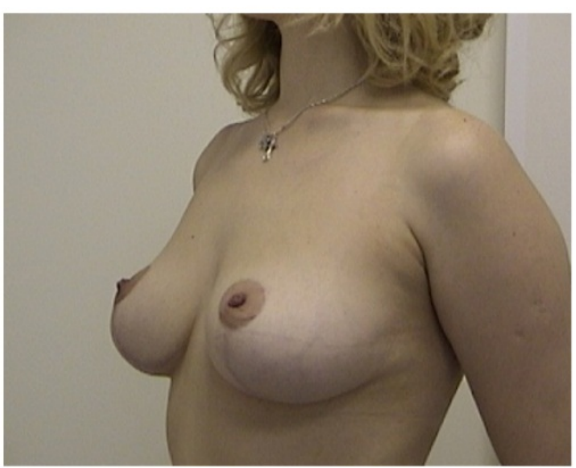

C

Figure 1. The result of classic mastopexy. The sight of the patient before (a); after 2 weeks (b) and a year after the operation (c) 
Such results can satisfy neither the surgeon nor the patient and make us doubt the worthiness of the classic mastopexy surgery in most cases of mastoptosis.

Long experience, watching the patients in the post-operation period, analysis of the performed surgeries made it possible to reveal the following reasons of the poor results:

- weakness of architectonics to which the pulled glandula mammaria is attached (banding of glandula mammaria masculus, a periosteal coverage of the feathers);

- incompetence of the overcast surgeon's seams;

- weak effectiveness of the devices which are aimed at supporting the pulled glandula mammaria from the bottom and the sides.

A logical decision was prompted - it is necessary to fix the pulled glandula mammaria to more indurated stable architectonics and provide a strong, steady cradle of the formed glandula mammaria in the lower and lateral portions. Such ideas were put into practice - the original technology was worked out: for the stable anchorage of the glandula mammeria, the technique of hanging the glandula mammeria on the collar bone with the use of special suture material was used, as for the improvement of a glandula mammaria form, strengthening and supporting of the pulled glandula mammaria in the remote postoperation period, cellular endoprosthesis or sutured under-running of the grandula mammaria were used. [7, 8].

The method, which we called "hypodermic bodice", has been successfully used since May 2002 for treating mild glandula mammaria ptosis. The suggested techniques of aesthetic mammoplasty gives an opportunity to get a satisfactory form of a glandula mammaria without post-operation cicatrices or with scarcely noticeable cicatrices in natural places and also to reach the longstanding strength of its form and high catastasis.

\section{Materials and methods}

\section{A. Materials}

During the performance of mastopexy in accordance with the offered method, the following surgical instruments and surgical materials are used.

Aptos Needle DRN 60 is a blunt-ended reflexive needle with an adherent polypropylene needle USP 0, 100 centimeters long. This tool is employed for instilling of the needle around the collar bone and stable anchorage of the glandula mammaria.

Aptos Needle 2/0 is a double-edged needle with a smooth retention suture of prolene 2/0, 100 centimeters long, fixed to the needle in the middle part of it. This unit has a knack for a double-sided patency, it allows to instill the needles under the skin and to perform subdermal under-running of soft tissues according to the broken or the lengthen boundary without skin dimpling with the result of the even pulled boundary (figure 3).

Mersilen specimen-grid holder Ethicon (Johnson \& Johnson, USA) is a holder in the thickness of 0.25 millimeters, the diameter of the stroma is $120 \times 85$ micron (figure 4 ). 


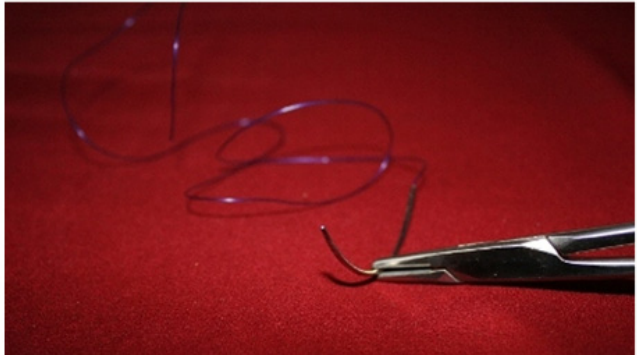

a

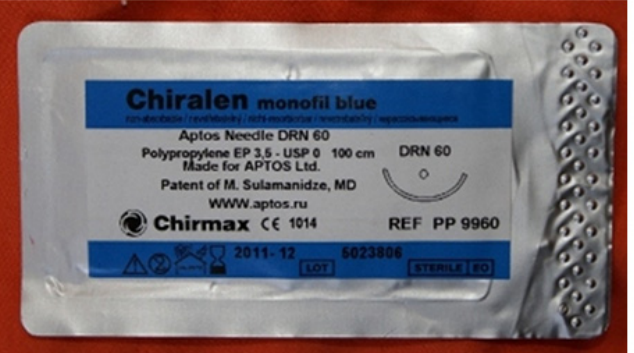

b

Figure 2. The needle with the suture Aptos Needle DRN 60 for instilling of the needle around the collar bone.

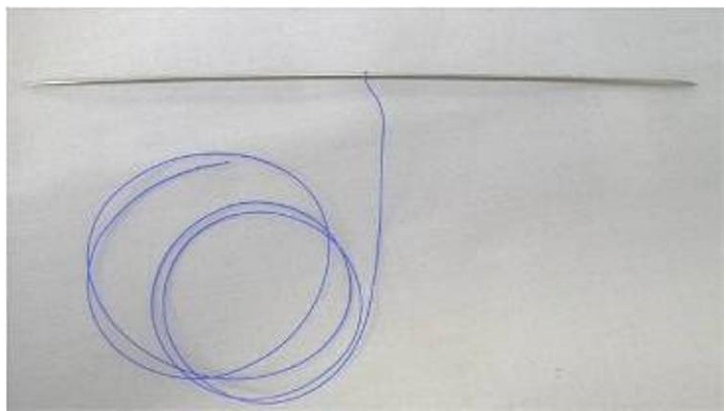

Figure 3. Aptos Needle $2 / 0$ is a needle with the suture for instilling of the glandula mammaria.

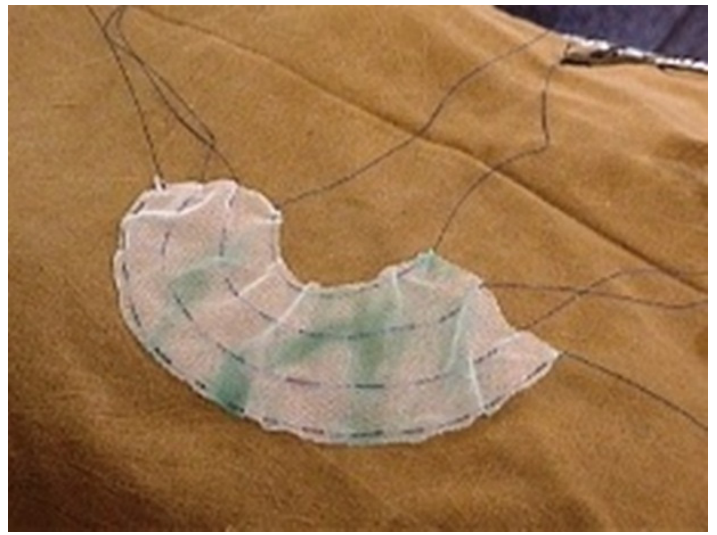

Figure 4. Mersilen speciment-grid holder Ethicon for instilling in the subdermal spatium of glandula mammaria.

Specimen-grid holder Breform (Breform ${ }^{\mathrm{TM}}$ Limited, RSA) which is made from a multifilament polyether in the form of a glandula mammaria (figure 5). It allows to make the result of the operation stable. 


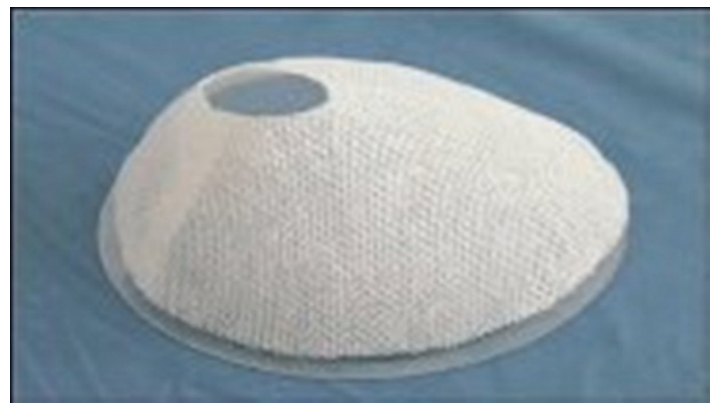

Figure 5. Polyether specimen-grid holder Breform made for anchoraging the results of mastopexy.

\section{B. Methods}

Our methods of minimally invasive breast mastopexy consist of anchoring the breasts (with the use of a cellular implant or under-running the breasts with sutures) and the follow-up mastopexy and hanging the breast on the clavicle.

Operational technique of suturing around the clavicle

The operation was performed under general anesthesia. The patient was laid down in a semi-sitting position. Two discissions, of 2-3 millimeters long each, were made along the midclavicular line: one was above the clavicle to its periosteal coverage, the second was lower, at the level of the second intercostal space to the banding of the greater pectorial muscle. The soft tissues were separated by a thin fastener like "mosquito" and hydropreporation of the soft tissues around the clavicle was performed as well (normal saline with epinephrine in amount of $20 \mathrm{ml}$ ).

A clavicular acus (Aptos Needle DRN 60) was taken with a heavy acutenaculum. It was inserted in the lower discission by its blunt end, instilled upward subdermal towards the clavicle and agested through the upper discission together with the suture. The suture was pulled with the acus, but the "tail", 10 centimeters long, was left in the lower maim. The acus was turned in the upper maim and the end of the acus was instilled around the collar bone, not separating from the bone. The acus with the suture was egested in the lower maim, where the nodosity with the left "tail" was tied.

Therefore, the path of the clavicular acus went from the lower maim subdermally in the adipose layer to the clavicle, then the path went behind it (postclavicular spatium) and next - under the banding of the internal surface of the greater pectorial muscle to the view of the lower maim, where the acus was egested to the maim through the fibers.

Two interrupted stiches of prolene 6/0 closed the maim over the clavicle at the end of the operation.

The most important stage of the whole operation is instilling of the acus behind the clavicle. In order to do it without any complications, it is necessary to perform the following actions: 
- make hydropreporation of the tissues behind and under the clavicle. This will allow moving the attached prescalenic musculus from the bone and enlarge the postclavicular spatium;

- $\quad$ turn the patients' head to the opposite side from where the operation is performed. For the pecroral arch, turn it below maximal. It will allow putting the clavicle forward and providing comfortable position for performing the operation;

- $\quad$ use only the recommended acus for instilling the suture, the bending and the length of which are aimed at the safe performance of the operation;

- move the end of the acus exactly along the bone without stopping the process; the surgeon can achieve it if he/she performs the semicircular movement of the acutenaculum carefully.

\section{Technique of the surgery on insertion of a reticular implant in the hypodermic spatium of the breasts (the method of the "hypodermic bodice")}

The surgery was performed under general anesthesia with the infiltration of the hypoderm by means of isotonic solution with adrenalin added.

The respective marking was made beforehand.

The patient was put in the semi-sitting position. Reticular implant was installed through the inframammar and the periareolary access. The length of the discission depended on the method of the surgical release of the cellulocutaneous flap. If this part of the operation was performed with the copper bent blunt-pointed scissors without endoscopic maintenance, the discission was made with the length of no less than 5 centimeters, while with the use of endoscopic equipment or a wire scalpel the length of the discission was no more than $2-3 \mathrm{~cm}$.

Detachment of the flap was done within the lower lateral and medial quadrants of the milk gland. A net was implanted and spread in the underflap area after hemostasis, which was later sewed with the interrupted stitch in the projection of the inframammar fold and the lower edge of the areola. 3-4 pairs of threads which had been sewed to the lateral and medial edges of the net were taken to the wound in the intercostal spatium under skin, where the thread had already been taken around the clavicle. Here they were taken out, pulled, and tied to the ends of the clavicularis thread, lifting the breasts as the result.

At the end of the operation two interrupted sutures were put on the wound in the area of the second intercostal space, while the main wound (under the areola and in the inframammar fold) was sewed in three stages by continuous method.

The important features of this operation are the following:

- the selection of the patients by indication;

- $\quad$ surgical release of the cellulocutaneous flap of such area which allows the net to seize a sufficient volume of the breasts subsequently, especially from the lateral side;

- the installation and straightening of the inserted net in the way that no "recesses" and roughness emerge, and only after that its fixation by the side seams;

- even alternating tightening of the threads with the control of the form of the lifted breasts and their stable tightening to the clavicular thread; 


\section{Technique of ligature sawing of the breasts (method of thread lifting of the breasts)}

The operation was performed under the general anesthesia with the patient in the semi sitting position.

The respective marking was made beforehand.

The middle clavicular line was drawn from top to bottom through the nipple to the inframammar fold, marking pints on that line: on the level of the second intercostal space (point A), the upper and lower edges of the areola. The distance from the lower edge of the areola to point $\mathrm{A}$ was divided into halves, this is where point $\mathrm{B}$ was marked, the segments $\mathrm{A}-\mathrm{B}$ and $\mathrm{B}$ - the upper edge of the areola were also divided into halves, where points $\mathrm{C}$ and D were marked.

By analogy points A1, B1, C1, D1 were marked below the areola. Oval lines were drawn through these points which outlined the breasts in different levels.

The operation was started with bayonet incisions, 1-1.5 centimeters in depths in points A, B, $\mathrm{C}, \mathrm{D}$, which were widened by blunt method with the use of the "mosquito".

Under-running of the breasts was performed with Aptos Needle 2/0. To perform that the point of the needle was inserted in the wound in point A and the thread was taken through under the skin according to the marking. The needle was partially taken out and turned if it was needed, moving it further according to the line of the marking until reaching the point of insertion, and it was taken out in point A. Then the thread was pulled out with its 5-7 centimeters ends left out and taken to the holder.

Under-running of the breasts according to the rest of the lines which had been drawn through points B-B1, C-C1, D-D1 of marking was done by analogy. Therefore, the breasts were fringed with threads in four levels. After that the threads were lifted and the ends were bound together alternately in the form of knots starting from point $\mathrm{A}$ to point $\mathrm{E}$.

Afterwards, with the use of the same blunt-pointed needle, the thread for under-running the clavicle (Aptos Needle DRN 60) was tied to the thread from point A to the thread from point C, the thread from $C$ to point $B$, the thread $B$ to the thread A, and the thread from this point to the thread which was fixed to the clavicle. In this way the breasts were lifted to the aesthetically acceptable form and position.

The important features of this operation are the following:

- the selection of the patients by indication;

- the insertion of the needle hypodermically at the necessary depths without visualization of the thread through the skin;

- under-running of the breasts in the way that in the areas of the entrance and the exit of the turn of the needle there are no retractions of the breasts left;

- even lifting of the threads and their tying together at the same level with the control of the required form. 
82 operations of aesthetic mammoplasty of breasts applying the method of sewing the breasts with threads, their lifting, and their suspension to the clavicle, 11 operations with the use of reticular implants have been performed in Total Charm clinics since 2002, in total 93 operations.

\section{Results}

The indications for undergoing such operations were considered to be:

- a small or a moderate ptosis of milk glands (I-II degree);

- a small size of the milk glands (relative size 1-2.5);

- a small or a moderate excess of skin;

- a small extent of involuntary changes of breasts tissues;

Operative intervention with these methods took place in cases of primary ptosis of breasts or of the recurrence of ptosis in the post-operation period. We have resorted to these methods for preventing the post-operation ptosis of breasts and in the presence of postoperation scars.

In practice, we have applied the first and the second or the first and the third operation.

In any plastic surgery when it is necessary to reduce the area of the skin one of the two wellknown methods are used. The first one - resection of the necessary amount of skin in the process of operational intervention, the second one - expecting its retraction, as long as the skin is known to shrink as the result of its release from the function of the long-lasting support of the substructural adipose, parenchymal, and other tissues, the value and the weight of which usually increases with the lapse of time. The second method in particular lies in the basis of some of endoscopic aesthetic operations and methods of thread face lifting. The same characteristic of the skin is taken into account and applied in the operation of "hypodermic bodice".

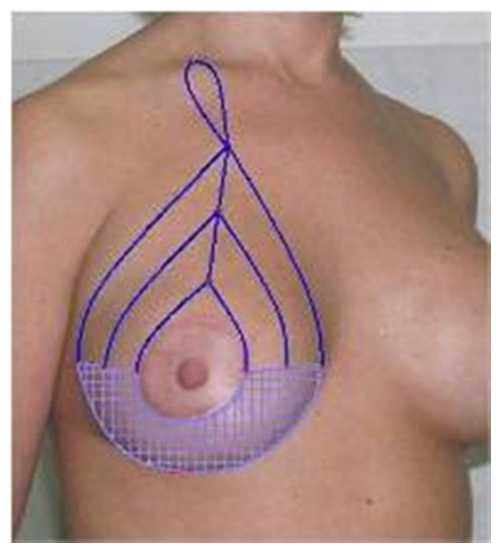

Figure 6. Scheme of marking the breasts for insertion of a reticular implant (the method of "hypodermic bodice"). 


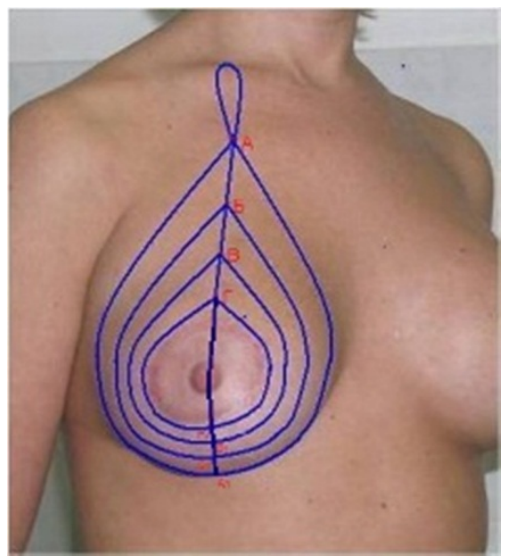

Figure 7. Scheme of marking of the breasts for under-running with the needles and the further lifting of the breasts (the method of the needle breast lifting).

The operational interventions were performed easily without extra trauma, the postoperation period in most cases did not show any after effects, while the aesthetic results were good and stable. In all cases the above mentioned method provided consistent, longlasting mastopexy.

The presented clinical results confirm the effectiveness of the operations performed (figures 8$13)$.

\section{Complications}

During the whole period of performing the operations we witnessed the following complications and unpleasant evidences:

- the case of failure of the hypodermic knot in point B from the left side on the 3rd day after the operation. As a result, ptosis recurrenc of the left breast and obvious skewness of the milk glands occurred (figure 14a);

Under the infiltrational anesthesia the wound in this place was opened, the ends of the threads were found and a new stable knot was put in place. The post-operation period did not show any complications and the final result was satisfying (figure 14b);

- the case of acquiring an atrophic indrawn scar, which was resolved with the method of lipofilling (figure 15a);

- $\quad$ some cases of skin indrawing in the places of the needle turns or of the skin-deep needle conduction. The defects were eliminated with the help of massage and the method of lipofilling;

We try to examine regularly the patients who were operated with these methods, as long as the methods are new and require special attention. We are usually interested in the following issues in the post-operation period: the condition of the milk gland near the reticule; the invasion of the reticule by the fibrous tissues; the condition of the clavicle; its 
stability, and the condition of the milk glands during menses, pregnancy, labour, lactation, and during the following period (figure 16).

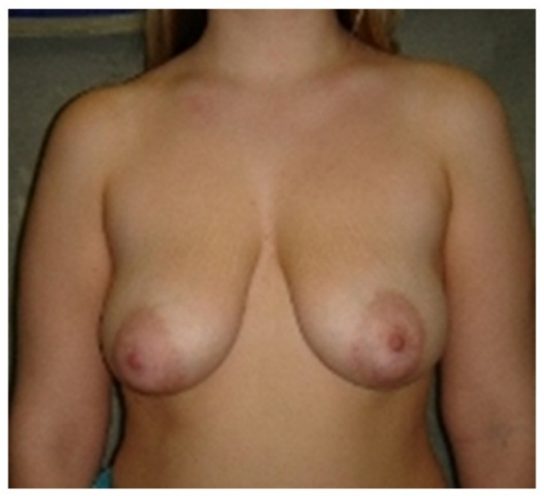

a

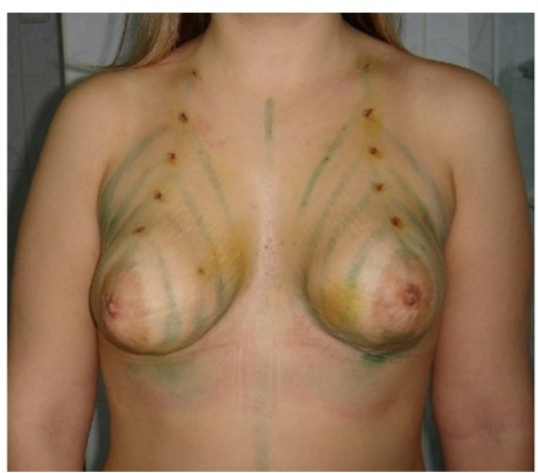

b

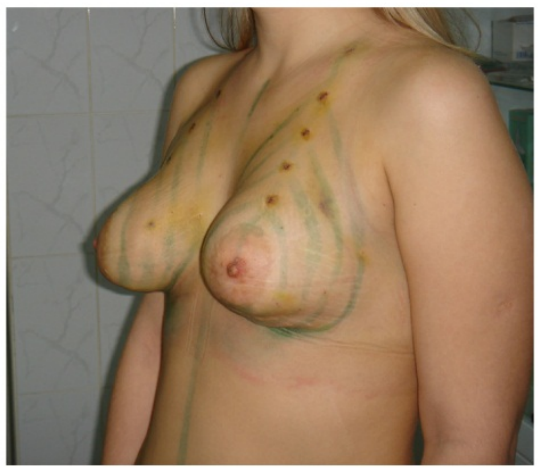

C

Figure 8. Patient A., 32 years old, before $(a, b)$ and in 2 days after $(c, d)$ the thread breasts lifting. 


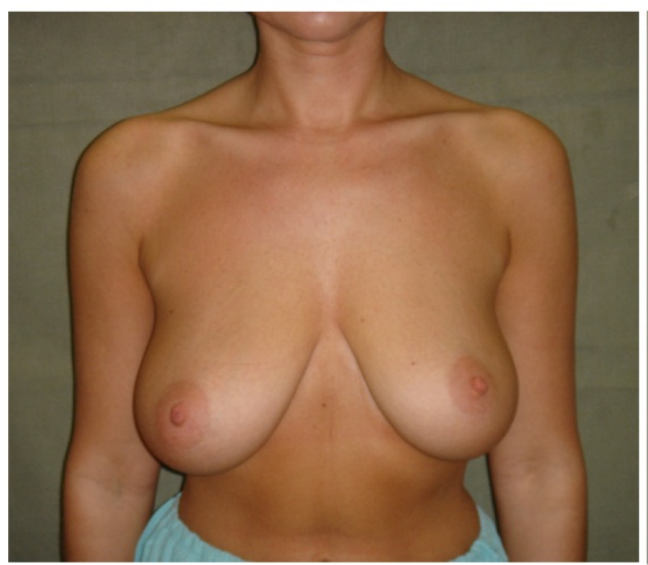

a

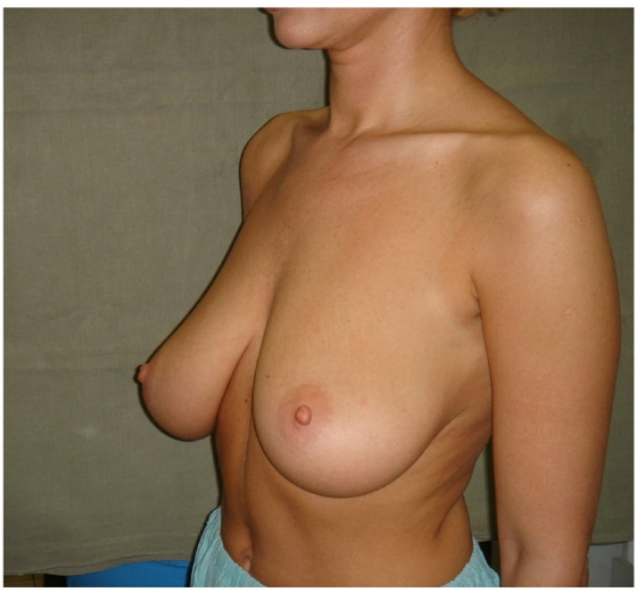

C

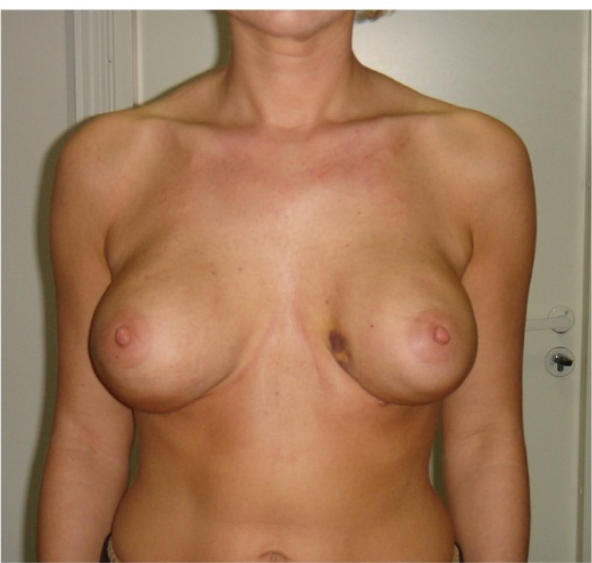

b

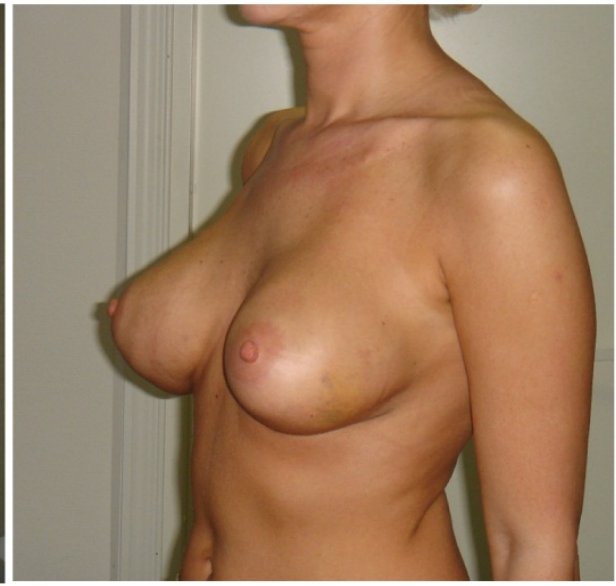

d

Figure 9. Patient B., 44 years old, before $(a, b)$ and in 10 days after $(c, d)$ the thread breasts lifting; 


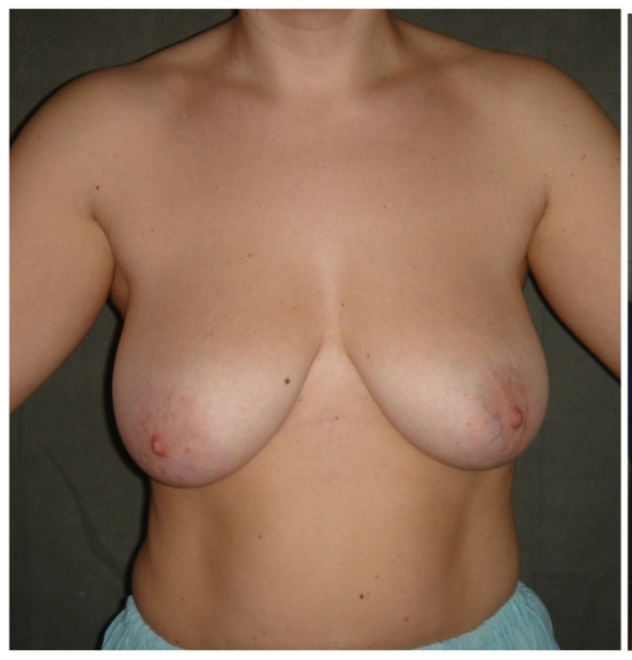

a

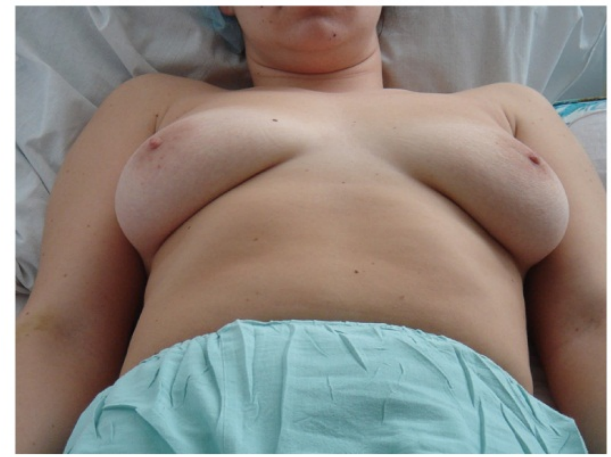

C

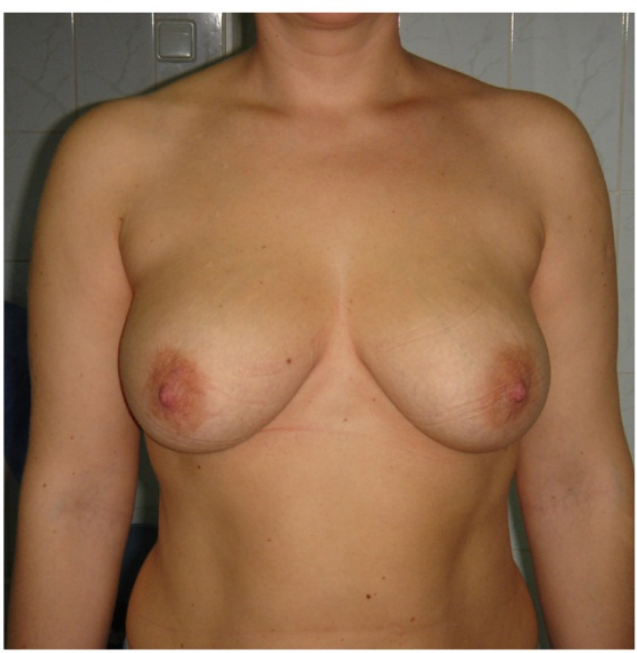

b

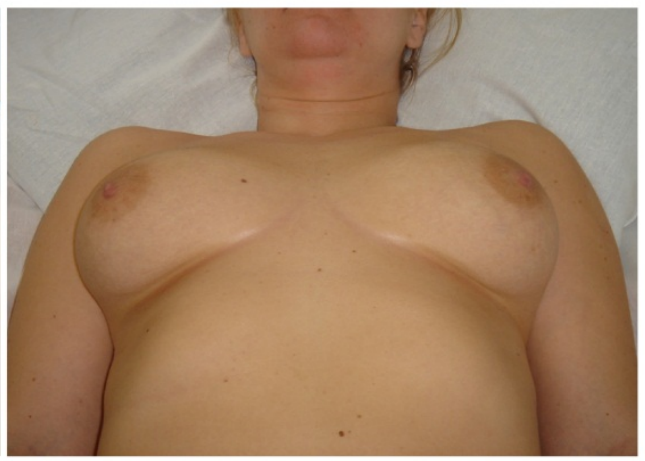

d

Figure 10. Patient C., 34 years old, before $(a, b)$ and in 2 years after $(c, d)$ the thread breasts lifting; 


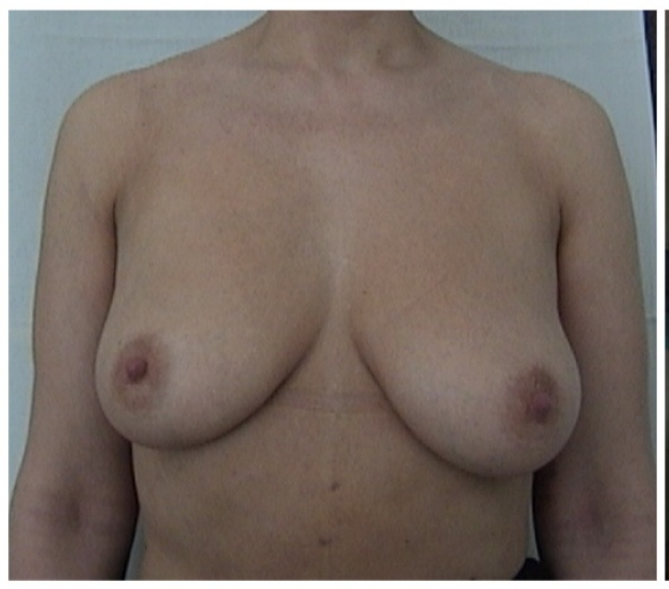

a

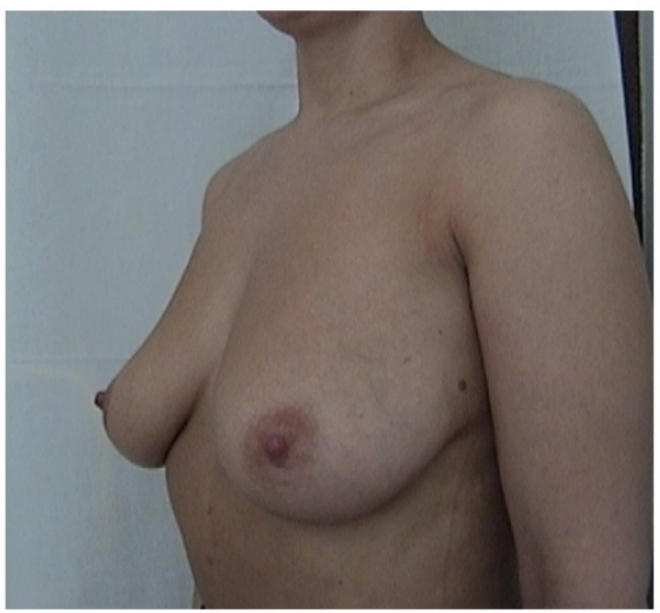

C

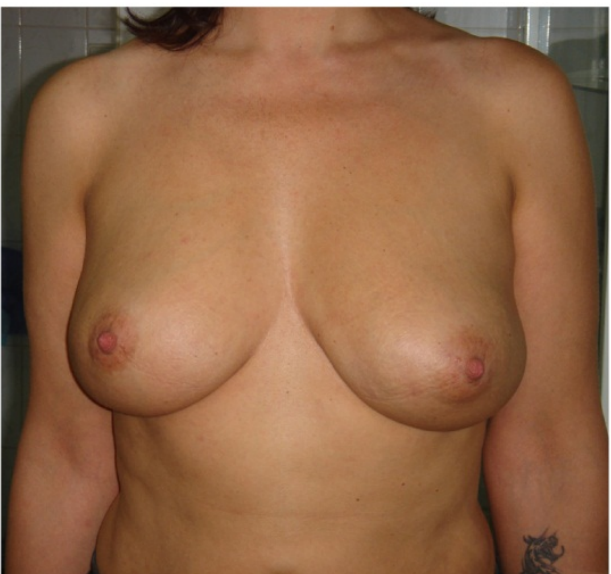

b

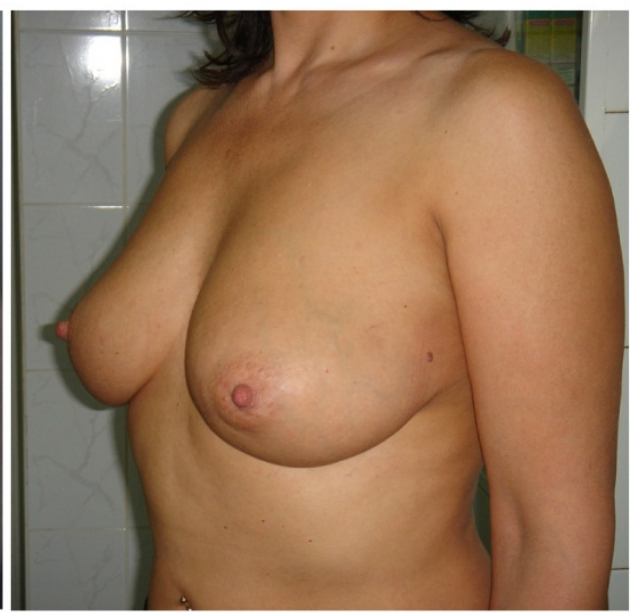

$\mathrm{d}$

Figure 11. Patient D., 34 years old, before $(a, b)$ and in 5 years after $(c, d)$ the operation with the use of a reticular implant. 


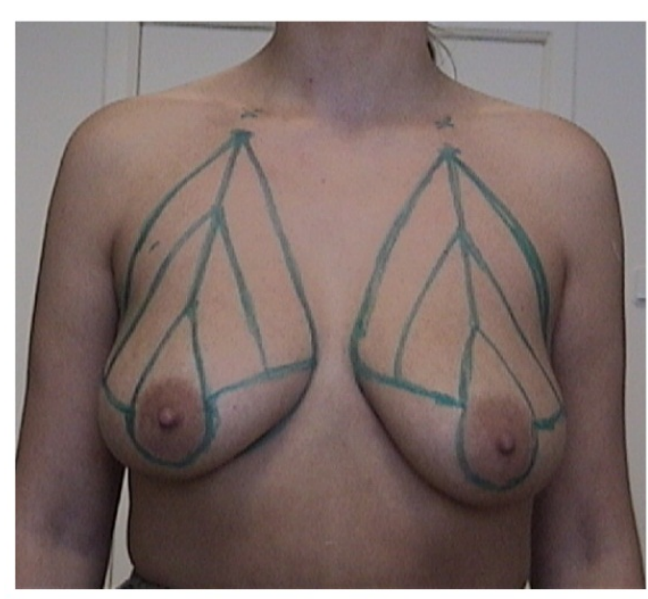

a

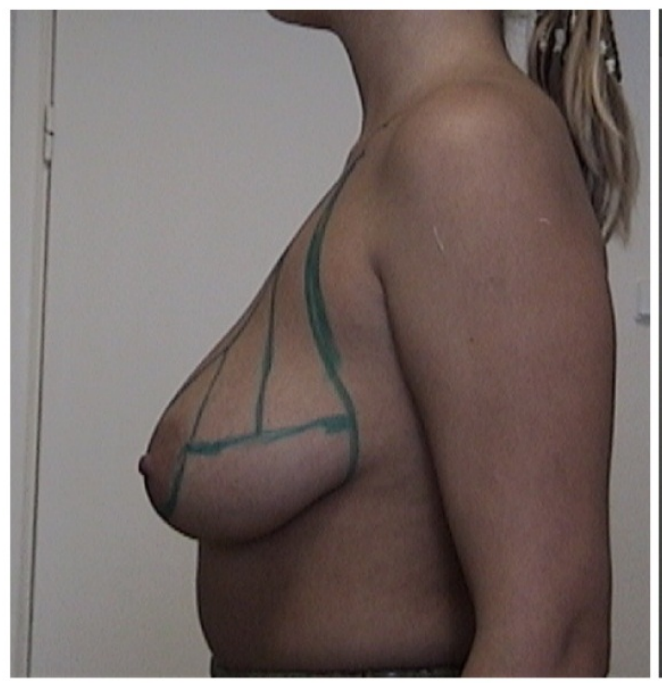

C

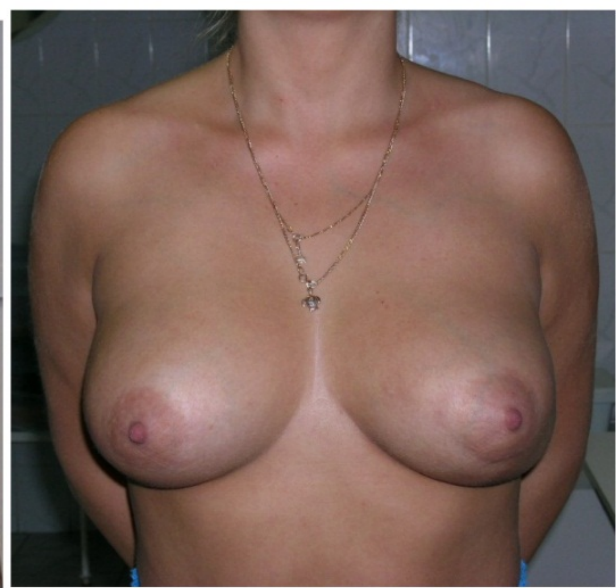

b

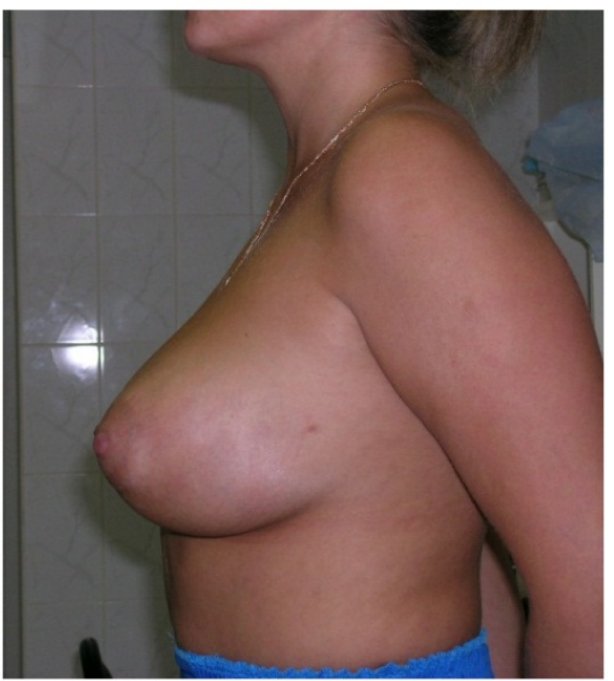

d

Figure 12. Patient $\mathrm{E}, 35$ years old, before $(\mathrm{a}, \mathrm{b})$ and in 2.5 years $(\mathrm{c}, \mathrm{d})$ after the breasts lifting with a reticular implant. 


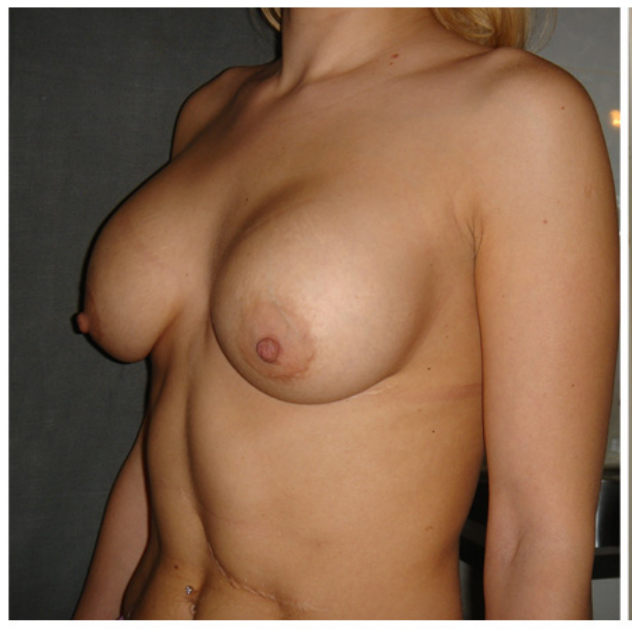

a

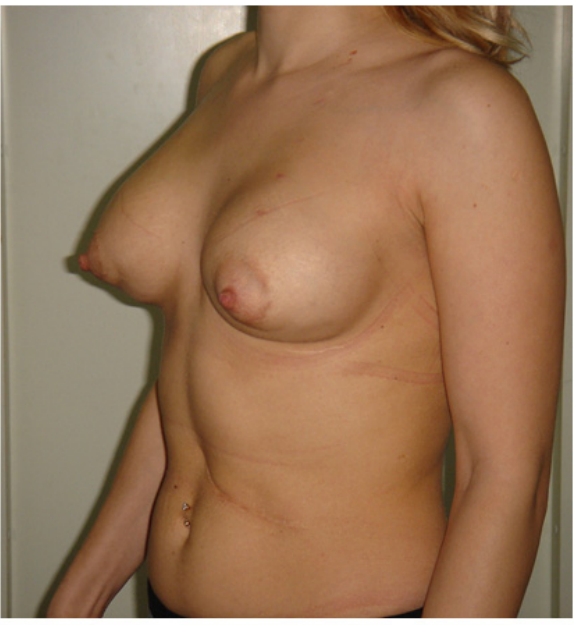

b

Figure 13. Patient $\mathrm{F}, 30$ years old. Some years ago the patient underwent augmentational mammoplastic in a different clinic. At the admission to our clinic she complained about the dissatisfying condition of her breasts. During the examination capsular contracture was observed. The implant remained in its place, while the tissue of the gland shifted down (glandulus ptosis). The patient underwent a thread breast lifting. Before (a) and in two months after the intervention (b).

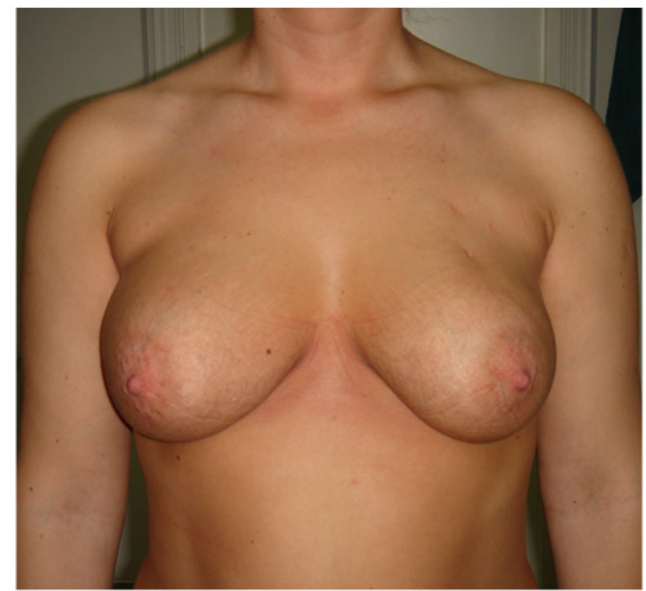

a

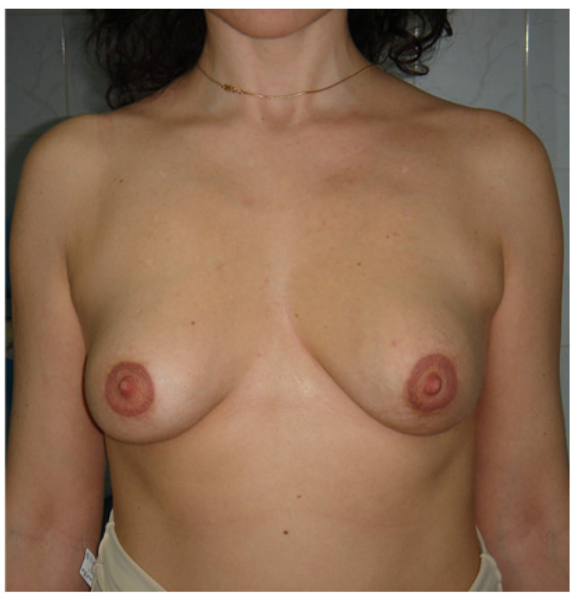

b

Figure 14. Patient $G$, 38 years old. Complication - failure of the thread knot in three days after the thread lifting recurrence of the left breast ptosis. Before (a) and in a year after the re-operation (b). 


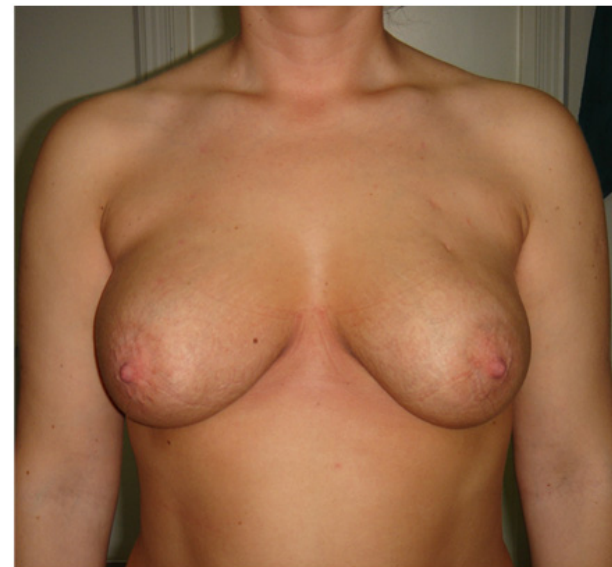

$\mathbf{a}$

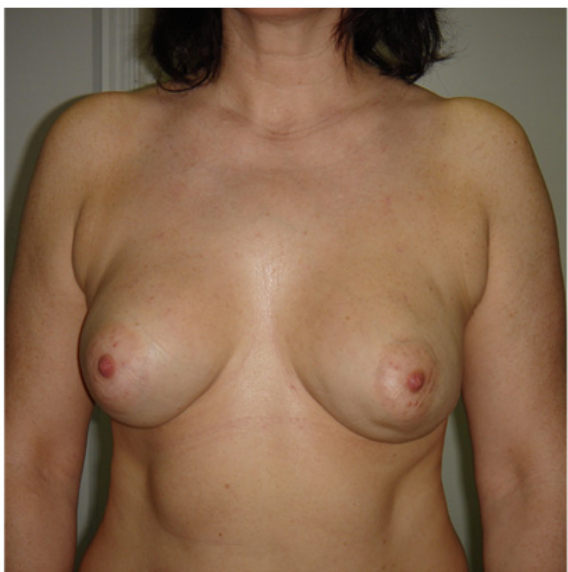

b

Figure 15. Complication - atrophic scarring (a); visualization of the threads - indrawing of skin in the areas of the turns of the needle and skin-deep needle conduction (b).

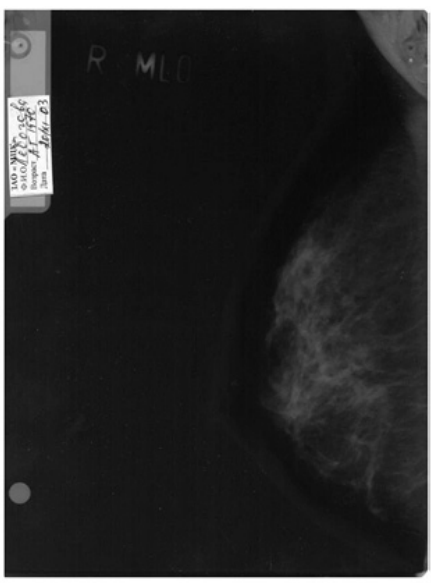

a

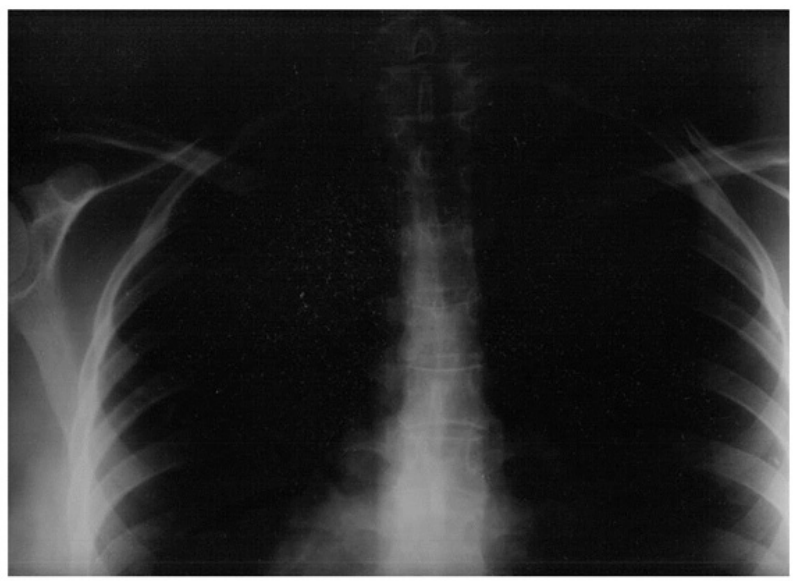

b

Figure 16. Patient E. X-ray examination of the breasts $(a, b)$ and the chest in two years after the breast lifting with installation of a reticular implant. 
Besides, in our practice there have been two cases of pregnancy, delivery, and further lactation. No problems were observed (figure 17).

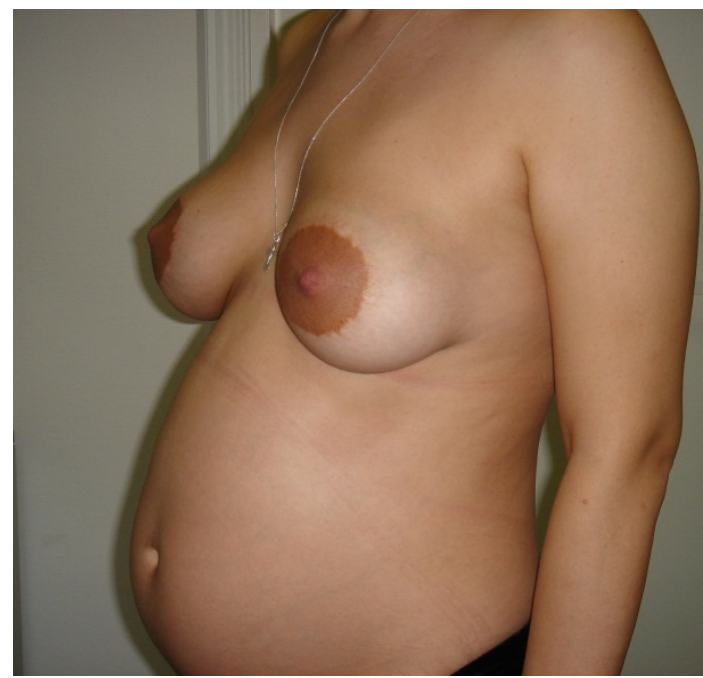

Figure 17. Patient $K, 28$ years old, in 2.5 years after the thread breast lifting, pregnancy period.

\section{Conclusions}

A group of surgeons of Total Charm clinic have presented the following methods and techniques, which serve to improve the results of mastopexy:

- suspension of the lifted breasts to the clavicle providing its stable attachment to the firm osteal structure, which does not allow the breast to move down gradually in the long run;

- insertion of a reticular implant in the hypodermic area of the lower and lateral segments of breasts, envelopment of these areas of the milk gland and its suspension to the clavicle, which leads to strengthening of the breasts and acquiring of the necessary aesthetically accepted form;

- thread sewing of the breasts through the cuts in the skin and its further suspension to the clavicle - girth of the milk gland from all the sides with solid surgical sutural material with application of hypodermic seams without incisions in order to create a resilient stroma of the gland with conical shape and to prevent its cephalic movement.

The first two methods are widely known in plastic surgery, but have been considerably modified by our group, the latter method is original and has been developed by the group.

Six-year period of performing mastopexy using "hypodermic bodice" method by underrunning of the breasts with Aptos threads, numerous examples and accumulated experience have shown that the method has justified the hopes. During the post-operation period, no patients have shown abnormal changes of milk glands, substructure, and the clavicle. No cases of dissatisfaction complaints have been reported. 
Also attention should paid to the method of hypodermic dissection of the soft tissues (to create a cellulocutaneous flap) which is performed with the use of wire scalpel (Aptos Wire). The operation is easy, simple and minimally invasive, without significant hemorrhage. In comparison with the endoscopic method, it does not require costly equipment and special training of the surgeon, while the post-operational rehabilitation of the patient is reduced. The acquired cellulocutaneous flap has even thickness, good blood supply, and survives well in the donor wound.

The presented methods of milk gland ptosis correction in combination with the use of reticular endoprosthesis for mastoptosis correction are regarded as promising areas in aesthetic surgery of minimal invasion, and they require further examination and accumulation of experience.

\section{Author details}

M. Sulamanidze, G. Sulamanidze and K. Sulamanidze

Clinic of Anaplastic and Aesthetic Surgery Total Charm, Moscow, Russia - Tbilisi, Georgia

\section{References}

[1] Adamyan A. A., Romashov Y.V., Kopiltsov A.A. Mammoplast in postlactational involution. Annals of plastic, reparative, and aesthetic surgery, 1997; (4);47-54.

[2] Borovikov A.M. Ter-Nokogosiyan G.A. Aesthetic mamoplast. What we talk about. Annals of plastic, reparative, and aesthetic surgery, 2002; (3);41- 46.

[3] Borovikov A.M. Milk gland ptosis. Selected issues of plastic surgery, 2005; 1(12).

[4] Burdin V.V. Beliyaev M.V. To the question of the choice of operational intervention in the postlactational involution of the milk glands. Annals of plastic, reparative, and aesthetic surgery, 2001; (2); 16-20.

[5] Milanov N.O., Startseva O.I., Chausheva S.I. Analysis of experience in single-stage mastopexy and endoprosthesis replacement of milk glands. Annals of plastic, reparative, and aesthetic surgery, 2005; (1); 44-51.

[6] Frishberg I. A. Surgical correction of cosmetic deflection of women's breasts. - Moscow, 1997.

[7] Sulamanidze M.A., Savchenko S.V., Vozdvizhenskiy I.S., Sulamanidze G.M., Osipov A.G.. Horisontal mammoplast. Annals of plastic, reparative, and aesthetic surgery, 2002; (3); 40-46.

[8] Sulamanidze M.A., Vozdvizhenskiy I.S., Sulamanidze G.M., Sulamanidze K.M. Application of reticular endoprosthesis in mamoplast. Our experience. Thesis collection II Intermational Conference "Modern technologies and opportunities of reconstructive and reparative aesthetic surgery". October 19-20, 2010 - Moscow, 2010. 